\title{
Mapping site index and volume increment from forest inventory, Landsat, and ecological variables in Tahoe National Forest, California, USA
}

\begin{tabular}{|r|l|}
\hline Journal: & Canadian Journal of Forest Research \\
\hline Manuscript ID & Cjfr-2016-0209.R2 \\
\hline Manuscript Type: & Article \\
\hline Date Submitted by the Author: & 12 -Sep-2016 \\
\hline Complete List of Authors: & $\begin{array}{l}\text { Huang, Shengli; US Department of Agriculture Forest Service, Region 5, } \\
\text { Remote Sensing Lab } \\
\text { Ramirez, Carlos; US Department of Agriculture Forest Service, Region 5, } \\
\text { Remote Sensing Lab } \\
\text { Conway, Scott; US Department of Agriculture Forest Service, Tahoe } \\
\text { National Forest } \\
\text { Kennedy, Kama; US Department of Agriculture Forest Service, Region 5, } \\
\text { Remote Sensing Lab } \\
\text { Kohler, Tanya; US Department of Agriculture Forest Service, Region 5, } \\
\text { Remote Sensing Lab } \\
\text { Liu, Jinxun; US Geological Survey, Western Geographic Science Center }\end{array}$ \\
\hline Keyword: & $\begin{array}{l}\text { site index, mean annual increment, timber productivity, remote sensing, } \\
\text { Sierra Nevada }\end{array}$ \\
\hline \multicolumn{2}{|l}{} \\
\hline
\end{tabular}


1 Mapping site index and volume increment from forest inventory,

\title{
California, USA
}

4

5 Shengli Huang ${ }^{a^{*}}$, Carlos Ramirez ${ }^{\mathrm{a}}$, Scott Conway $^{\mathrm{b}}$, Kama Kennedy ${ }^{\mathrm{a}}$, Tanya Kohler ${ }^{\mathrm{a}}$, Jinxun 3237 Peacekeeper Way, Suite 201, McClellan, CA 95652

*Corresponding author. shenglihuang@fs.fed.us

\author{
b 10811 U.S. Forest Service, Tahoe National Forest, Stockrest Springs, Truckee, CA 96161 \\ ${ }^{\mathrm{c}}$ USGS Western Geographic Science Center, 345 Middlefield Rd, Menlo Park, CA 94025
}




\section{Abstract}

15 High-resolution site index (SI) and mean annual increment (MAI) maps are desired for local

16 forest management. We integrated field inventory, Landsat, and ecological variables to

17 produce $30 \mathrm{~m} \mathrm{SI}$ and MAI for the Tahoe National Forest (TNF) where different tree species

18 coexist. We converted species-specific SI using adjustment factors. Then, the SI map was

19 produced by (1) intensifying plots to expand the training sets to more climatic, topographic,

20 soil, and forest reflective classes, (2) using results from a stepwise regression to enable a

21 weighted imputation that minimized the effects of outlier plots within classes, and (3) local

22 interpolation and strata median filling to assign values to pixels without direct imputations.

23 The SI (reference age is 50 years) map had an $\mathrm{R}^{2}$ of 0.7637 , a root-mean-square error (RMSE)

24 of 3.60, and a mean absolute error (MAE) of 3.07 meters. MAI was similarly produced with

25 an $\mathrm{R}^{2}$ of 0.6882 , an RMSE of 1.73 , and a MAE of 1.20 cubic meters per hectare per year.

26 Spatial pattern and trend of SI/MAI were analyzed to be related to elevation, aspect, slope,

27 soil productivity, and forest type. The 30m SI and MAI maps can be used to support decisions 28 on fire, plantation, biodiversity, and carbon.

29

30 Key words: site index, mean annual increment, timber productivity, remote sensing, Sierra

31 Nevada 


\section{1. Introduction}

33 Forest productivity is an important indicator of diverse applications such as biofuels supply, 34 carbon sequestration, and forest growth projection. In the western United States (US), 35 potential productivity is assessed by the Forest Inventory Analysis (FIA) program whereby 36 site trees are selected to produce a site index (SI) for forest field plots (Latta et al., 2009). SI 37 is a common species-specific approach in forestry for assessing forest site productivity; it is 38 defined as the height of dominant trees of a stand projected to some particular reference age, 39 using specific tables and equations for each forest species differing by region (Curt et al., 40 2001). Mean annual increment (MAI), defined as the increment (increase in volume) of a 41 timber stand averaged over the period between age zero and the age at which MAI culminates 42 (i.e., reaches its maximum value), is used in economic analysis and determinations of forest 43 policy because it can be associated with value and rate of return on investment. From different 44 aspects, both SI and MAI can help evaluate the quality of the land and predict timber 45 productivity, wood volume, and potential rate of forest growth, important for local forest 46 management such as silviculture, ecological restoration, and habitat conservation. Ideally, 47 spatially continuous maps, including SI and MAI, at detailed to moderate resolutions (e.g., 1$4830 \mathrm{~m}$ ) are needed for tactical planning and operational forest management (Falkowski et al., 49 2009). The maps at this detail provide the greatest flexibility for meeting the widest variety of 50 forest information needs by allowing researchers and forestry practitioners to tailor analyses

51 to meet particular objectives (Brosofske at al., 2014). However, high resolution spatially52 explicit SI and MAI products are usually not available. 
53 Historically, spatial site productivity data have been based on soil maps from the Natural

54 Resource Conservation Service (NRCS) that lacked the accuracy required for project level

55 planning or site studies. In particular, the FIA program collects forest information in the field;

56 however, to preserve confidential information for private land owners, the U.S. Farm Bill

57 specifically requires that the reported positions of FIA plots be perturbed from their actual

58 coordinates. To greatly enhance the utility of FIA data, one of the proposed alternatives is to

59 provide a variety of model-based maps of forest attributes that users could access via the

60 Internet (McRoberts at al., 2005). However, it is difficult to map forest growth potential

61 across regions with different environmental conditions from limited field measurements of

62 productivity (Waring et al., 2006; Weiskittel et al., 2011). Despite the difficulties, several

63 different methods have been used to map SI and MAI. Correlating SI with site types

64 according to a local or regional site classification system was reported (Curt et al., 2001).

65 Parametric regression and statistical models have been commonly used to predict SI and MAI

66 from biophysical factors related to climate, soil, and topography (e.g., Brandl et al., 2014;

67 Fries et al., 2000; Hamel et al., 2004; Monserud et al., 2006; Sharma et al., 2012; Wang and

68 Klinka, 1996). Nonparametric random forest models have been developed to relate SI as a

69 function of climate variables (Crookston et al., 2010; Jiang et al., 2015; Weiskittel et al.,

70 2011), and random forest was also combined with regression models for predicting plantation

71 loblolly pine (Pinus taeda L.) SI from biophysical variables (Sabatia and Burkhart, 2014).

72 Geostatistical techniques such as simplified universal kriging (UK) were also adopted to

73 predict SI for six major tree species in the German state of Baden-Württemberg based on large

74 data sets from forest inventories (Nothdurft et al., 2012). A biophysical SI method, which

75 obtains the SI of a given site by making adjustments to a mean provincial SI using multipliers 
according to site climatic, edaphic, and stand structural properties, was proposed by Ung et al. (2001) and applied by Beaulieu et al. (2011) to predict SI for seven plantation-grown conifer species in Quebec. Modeling approaches such as the Physiological Processes to Predict Growth (3-PG) model were used to generate estimates of SI and potential productivity (Coops et al., 2011; Swenson et al., 2005). Based on spatially-explicit climate data and point-specific productivity data, Latta et al. (2009) evaluated four possible imputation methods (nearest neighbor, multiple linear regression, thin plate spline functions, and a spatial autoregressive model) to produce culmination potential MAI for all of Oregon and Washington timberland at 800m resolution. Waring et al. (2006) used the mid-summer Moderate Resolution Imaging Spectroradiometer (MODIS) Enhanced Vegetation Index (EVI) values to generate a $1 \mathrm{~km}$ resolution map predicting spatial variation in SI of Douglas-fir over $630,000 \mathrm{~km}^{2}$ in the Pacific and Inland Northwest, U.S.A.

All these previous efforts provide different solutions to SI and MAI mapping, but they have three drawbacks. First, high resolution remote sensing data, such as $30 \mathrm{~m}$ Landsat, have been rarely used, although Ma et al. (2006) ignored the biophysical factors and predicted the spruce-dominant forest-ecosystem site index from Landsat vegetation index based on a simple linear correlation. Second, very few studies were reported for a landscape where many trees species coexist but a specific species is only found in a limited area. Third, although there are many methods (e.g., regression, random forest, and nearest neighbor) to map and predict inventory attributes for operational forest management, each method has its own advantage and disadvantage, as reviewed by Brosofske at al. (2014). For example, parametric regression approach relies on data assumptions and cannot easily handle missing values. Nearest neighbor approach is sensitive to the spatial mismatch caused by poor georeferencing of 
99

100

101

102

103

104

105

106

107

108

109

110

111

112

\section{$113 \quad 2$. Study area}

114 Our study area is the TNF located in northern California's Sierra Nevada with a total area of

$1153526.82 \mathrm{~km}^{2}$ (Figure 1). This area is renowned for its rugged extremes, ranging from an

116 elevation of $457 \mathrm{~m}$ on the western edge of the forest to over $2865 \mathrm{~m}$ on mountain tops along

117 the Sierra Crest. The western third of the area is dominated by deeply incised canyons that are

118 separated by long, narrow, gently sloping ridges; however, the eastern third is featured by low

119 foothills and broad valleys. The study area is a temperate ecosystem with many tree species

120 that coexist in a heterogeneous environment. The study area generally experiences warm dry 
121 summers and cold wet winters, but elevation plays a major role in distribution of weather

122 conditions. Winter temperatures below zero and summer temperatures above $37.8^{\circ} \mathrm{C}$ indicate

123 the normal seasonal spread. Temperatures range from very warm in the canyons in the

124 western part during summer to very cold in the high areas and eastern parts in the winter. The 125 precipitation falls mainly from October through April, but it typically comes in the form of 126 snow at higher elevations. The soils on the TNF were formed under the combining properties 127 of physiography, topographic relief, hydrology, vegetation, and geomorphology. The TNF has 128 a variety of soil types with productivity ranging from very low to very high, according to 129 "Soil Survey Tahoe National Forest Area California" 130 (http://www.nrcs.usda.gov/Internet/FSE MANUSCRIPTS/california/tahoeNFCA2002/tahoe

131 NFCA2002.pdf). TNF also has some of the most productive forest lands in the US and it is 132 home to a large variety of conifer and deciduous trees. The dominant species include red and 133 white fir (Abies magnifica and Abies concolor), ponderosa pine (Pinus ponderosa), sugar pine 134 (Pinus lambertiana), incense-cedar (Calocedrus decurrens), and California black oak 135 (Quercus kelloggii). Local managers requested a high-resolution SI and MAI map to capture 136 the heterogeneous landscape for forest management. Insert figure 1 around here

$140 \quad 3.1$ Datasets 
142 A Landsat 5 Thematic Mapper (TM) image with path 43 and row 33 acquired on September 14327,2011 was collected. The data were processed into surface reflectance data with LEDAPS 144 algorithm (Masek at al., 2006).

145

146 147 148 149 150 151 152 153

\subsubsection{SI and MAI from FIA}

The FIA program has established field plot centers in permanent locations. The inventory plots consist of four 7.32-m fixed-radius subplots spaced $36.6 \mathrm{~m}$ apart in a triangular arrangement with one subplot in the center and three peripheral subplots located at $36.58 \mathrm{~m}$ from the center of the central subplot with azimuths of $0^{\circ}, 120^{\circ}$, and $240^{\circ}$. In each plot, the field crew selected and measured the site trees according to field protocol. A total of 225 homogeneous plots with the site tree species were selected (Figure 1). These plots were collected in different years ranging from 2003 to 2015. In this study, 205 of the 225 FIA plots were randomly used to produce maps and the remaining 20 plots were withheld for accuracy assessment. The actual plot locations were used rather than the perturbed locations. We retrieved plot level SI (with reference age of 50 years) from the FIA database. In addition, in each plot all the survey trees were used by the FIA program to determine the forest type of the plot (Figure 2). We calculated the MAI for each plot from the plot SI with different equations that were derived from yield data found in published normal yield tables (Table 1).

\section{Insert figure 2 around here}

\section{Insert table 1 around here}

For a regional SI mapping, SI measurements covering different landscape are desired. However, a specific species may only be found in a limited area (e.g., most of the California red fir site trees were located in the center portion of our study area, as shown in Figure 1), and the SI from different species cannot be combined directly because SI is species specific. 
165 Nevertheless, the SI for different species are correlated (Keyser et al., 2008), and a reasonable 166 relationship exists to convert the SI of different species to a regional site index (RSI, equation 167 1) so that they can be comparable to reflect site quality:

168

169

170

171

172

173

174

175

176

$\mathrm{RSI}=\mathrm{SI} / \mathrm{F}_{\mathrm{S}}$

where RSI is the regional site index adjusted from species-specific SI (height in meters with reference age of 50), and $F_{s}$ is the species-specific adjustment factor (Table 2). $F_{s}$ was determined by Keyser et al. (2008) to convert the 50-year SI of individual species in the western Sierra Nevada to reflect the site quality, ranging from 0.45 to 1.0 . The adjustment resulted in a new RSI for each plot, which can be comparable and applied to a spatially continuous regional mapping.

\section{Insert table 2 around here}

\subsubsection{Climate, topography, and soil zones}

SI and MAI are affected by ecological factors such as climate, topography, and soil; therefore, we compiled three ecological classifications to represent these factors (Figure 3). For climate, four raster datasets of 270m Actual Evapo-Transpiration (AET), climatic water deficit (CWD), January mean temperature $\left(\mathrm{T}_{\mathrm{jan}}\right)$, and July mean temperature $\left(\mathrm{T}_{\mathrm{jul}}\right)$ over the entire California were obtained (Flint et al., 2013). A Random Forest technique (Breiman, 2001), which is a classification method that operates by constructing a multitude of decision trees at training time and then outputting the mode of the classes of the individual trees, was used to classify California into 100 zones and the portion of our study area was clipped, resulting in 52 zones

(Figure 3a). For topography, we used the Landscape Management Unit (LMU) tool version 2 
188 (North, 2012) to divide the study area into 6 types based on a 4m Digital Elevation Model 189 (DEM). These 6 zones represented distinctions in slope, aspect, and relative position (e.g., 190 canyon and ridge) (Figure 3b). The soil productivity information was compiled from the 191 forest survey site class of Soil Survey Geographic (SSURGO) database 192 (http://websoilsurvey.sc.egov.usda.gov/App/WebSoilSurvey.aspx), resulting in 9 zones 193 (Figure 3c).

194

195

\subsubsection{Integrated Biosphere Simulator (IBIS) productivity}

196 The Integrated Biosphere Simulator (IBIS) (Foley et al., 1996; Kucharik et al., 2000) is a 197 physically consistent modeling framework that follows basic rules of physics, plant 198 physiology, and biogeochemistry. Through another project, a 1km resolution, 1901-2010 IBIS 199 simulation was performed. The simulation was driven by PRISM monthly precipitation and 200 temperature data (http://prism.oregonstate.edu) and the SSURGO soil data. We then 201 summarized the mean of the simulated total biomass carbon (unit: $\mathrm{kg} \mathrm{C} \mathrm{m}^{-2}$ ) between year 70 202 and year 110 (Figure 3d). This gives the general spatial distribution of forest productivity. 203 We classified the productivity into 3 zones of " $<5$ ", "5 10", and " $>10 "$.

\subsubsection{Overview}

207 To extrapolate field SI and MAI to a spatially continuous map, we assigned the SI and MAI 208 value for each $30 \mathrm{~m}$ pixel with a new computer tool called "Field And SatelliTe for Ecosystem 209 MAPping” (FastEmap, Huang et al., 2016). The tool assimilates measured point-specific 
210 estimates of forest biophysical characteristics, satellite images, and auxiliary datasets to map

211 forest parameters at a $30 \mathrm{~m}$ resolution. The tool consists of four major modules, which are

212 defined below, including: a) intensifying plots; b) conducting a stepwise regression; c)

213 imputation with regression as weights, and d) local interpolation and strata median filling. In

214 general, the first step of "intensifying plots" assigns the attribute of a field plot to those pixels

215 that are "extremely similar" so that the training sets can be expanded to more climatic, 216 topographic, soil, and forest reflective classes (see section 3.2.2). The second step of 217 "stepwise regression" provides a map prediction on measured metrics to capture the general 218 distribution of forest attributes, enabling a subsequent weighted imputation (see section 3.2.3).

219 The third step of "imputation" is to divide the study area into many groups composed of 220 similar pixels. The weighted mean of plots falling within a specific group is assigned to the 221 group; weighting is inversely proportional to the differences between measurement and 222 regression for minimizing the effects of outlier plots within groups (see section 3.2.4). The 223 last step of "local interpolation and strata median filling" is to assign values to pixels without 224 direct imputations (see section 3.2.5). This flowchart was applied to SI and MAI separately 225 and in this section, we have taken SI to illustrate the procedure (Figure 4).

Insert figure 4 around here

\subsubsection{Intensifying plots by creating additional "virtual" plots}

228 Imputation methods usually require a lot of field data, which is confirmed by the simulation 229 study of Nilsson (1997) who showed that at least one plot per $26 \mathrm{~km}^{2}$ was required for his 230 study. However, in many cases the plot spatial sampling frequency may be too sparse to 231 provide adequate reference data for a typical project area extent (Hudak at al., 2014); 232 therefore, the main purpose of creating additional "virtual" plots from existing FIA plots was 
233 to solve potential problems stemming from insufficient field plot numbers (Huang et al., 234 2016). A plot intensification methodology was adopted by previous studies to address similar 235 problems. For example, Breidenbach et al. (2012) created 580 artificial sample plots and then 236 aggregated them with 154 measured sample plots to improve above-ground biomass 237 predictions.

238 Intensifying plots was accomplished by assigning a SI of an FIA plot to those "extremely 239 similar" pixels as follows. Assuming a) an FIA plot is falling in climate zone X, topography 240 zone Y, and soil zone Z; b) The reflectances of Landsat bands 3, 4, 5 and 7 of this plot are R1, $241 \mathrm{R} 2, \mathrm{R} 3$ and R4, respectively; and c) the SI of this plot is V, then a SI of V was assigned to 242 those pixels that met the following criteria: a) they were in the same climate zone $\mathrm{X}$, 243 topography zone $\mathrm{Y}$, and soil zone Z; b) their reflectances of Landsat bands 3, 4, 5, and 7 fell 244 within "R1 $\pm \alpha$ ", "R2 $\pm \alpha$ ", "R3 $\pm \alpha$ ", and "R4 $\pm \alpha$ ”, respectively, where $\alpha$, an empirical 245 threshold value defining "closeness", was set as 0.01. All original FIA plots and the new 246 pixels that were assigned a SI value (virtual plots) were combined as "intensified plots". This 247 step of "intensifying plots" resulted in 5590 intensified plots, 27 times the original number of 248205 plots. One should be aware that the procedure of "intensifying plots" simply duplicates 249 the attribute from the existing plots and cannot enhance the variation, so there was no 250 additional information being created; however, it creates more plots distributed in spatial 251 domain.

\section{$252 \quad 3.2 .3$ Stepwise regression}

253 Regression is a traditional analysis approach to predict inventory attributes from limited field 254 plots, so a regression was conducted to create a SI map. To do this, the 205 FIA plots were 255 overlaid with AET, CWD, $\mathrm{T}_{\mathrm{jul}}, \mathrm{T}_{\mathrm{jan}}$, soil productivity (SP), and Landsat bands 1, 2, 3, 4, 5, and 
2567 to extract the values, and a SI map (Figure 5) was produced from the stepwise regression 257 (equation 2).

258

$\mathrm{SI}=\left(1.58 \mathrm{~T}_{\mathrm{jan}}+0.0028 \mathrm{~B}_{4}-0.052 \mathrm{~B}_{1}-0.56 \mathrm{~T}_{\mathrm{jul}}+0.034 \mathrm{~B}_{3}-0.018 \mathrm{~B}_{7}+0.51 \mathrm{SP}+0.0088 \mathrm{~B}_{5}-8.41\right)$

259 The $\mathrm{R}^{2}$ of this regression was 0.29 , indicating a low accuracy. However, the general 260 distribution of SI was reasonable: high SI tended to be located in warmer areas and in the low

261 foothills while areas of low SI were typically found in the colder regions and in the high 262 mountain tops. This indicated that the stepwise regression could capture the general pattern of 263 SI, which led us to use it for calculating weights in the following imputation process.

\subsubsection{Group imputation weighted by regression}

266 In forestry, the "stratum/stand mean" technique has been used for mapping. For example, in 267 estimating forest stand characteristics, Muinonen at al. (2001) superimposed the stand 268 boundaries on the field plots and calculated stand results from plots falling within stand 269 boundaries. Within the study area of McRoberts (2008), the boundaries of 12 representative 270 stands were delineated and stand-level means for each variable were estimated as means over

271 plots within stands. A similar concept was adopted in our following group imputation process 272 but in an iterative manner.

273 After intensifying plots (section 3.2.2) and stepwise regression analysis (section 3.2.3), the 274 study area was divided into many groups through two steps. First, Landsat bands 3, 4, 5, and 7 275 were each equally binned into 15 classes. Second, we used the ArcGIS "combine" function to 276 combine these Landsat classes with 52 climate zones (Figure 3a), 6 topography zones

277 (Figure 3b), and 9 soil zones (Figure 3c) to create $15 \times 15 \times 15 \times 15 \times 52 \times 6 \times 9=142155000$ 
278 unique groups. In this way, each group is composed of similar pixels having similar remote

279 sensing metrics and environmental conditions. In each group, the intensified plots falling

280 within a group were identified, and then equation (3) was used to calculate the SI for all the

281 pixels in this group:

$282 \quad S I_{\text {group }}=\sum_{k=1}^{n} W_{k} \times S I_{m-k}$

283 where $\mathrm{n}$ is the number of intensified plots located within the group, and $\mathrm{SI}_{\mathrm{m}-\mathrm{k}}$ indicates the SI

284 for the $\mathrm{k}^{\text {th }}$ plot. $\mathrm{W}_{\mathrm{k}}$ is the weighting coefficient for the $\mathrm{k}^{\text {th }}$ plot, which is inversely related to its 285 absolute difference between field $\mathrm{SI}\left(\mathrm{SI}_{\mathrm{m}-\mathrm{k}}\right)$ and regression predicted $\mathrm{SI}\left(\mathrm{SI}_{\mathrm{p}-\mathrm{k}}\right)$ (equation 4):

$W_{k}=\left(\left|S I_{m-k}-S I_{p-k}\right|\right)^{(-t)} / \sum_{k=1}^{n}\left(\left|S I_{m-k}-S I_{p-k}\right|\right)^{(-t)}$

286 where $t$ was set as 2 and $\mathrm{k}$ was set as $>3$, which means at least 4 plots were required to fall in

287 the group in order to perform imputation. The main reason for adopting weighting was that

288 there were possible spatial mismatches between field plots and remote sensing images (e.g., 289 the coordinates of our FIA plots had errors ranging from less than $10.1 \mathrm{~m}$ to larger than 30.8

$290 \mathrm{~m}$, if only assessed from the Global Position System instrument), thus creating possible 291 outliers within each group. For example, a high-biomass forest plot may fall in an adjacent 292 low-biomass shrubland due to its Global Position System error. In this case, the falsely293 located plot would cause the shrubland biomass to be overestimated if not properly handled. 294 However, regression prediction can capture the general distribution of high biomass in forest 295 and low biomass in shrubland. If the weighting was calculated as the inverse absolute 296 difference between measured biomass and regression predicted biomass, a low weighting will 
297 be assigned to this falsely-located plot for shrubland biomass prediction, thus reducing the 298 influence of spatial mismatch. See more details in Huang et al. (2016).

299 When there was an insufficient number of plots within a specific group, we ignored the soil 300 zone and then conducted the imputation again. If the number of plots was still insufficient, we 301 ignored the topography zone. This iteration was repeated until the climate zone was ignored. 302 In other words, we chose which environmental characteristics were most important and 303 dropped them from the imputation process in reverse order of importance. Even after all of 304 climate, topography, and soil constraints were ignored, it was still possible that insufficient 305 plots were located within a group. In this case, we reduced the number of Landsat bins from $306 \quad 15$ to 10 and repeated the above steps.

307 From the aforementioned context, we can see the SI was imputed in an iterative manner. It 308 started with a high bin number and many condition constraints for imputation, then iteratively 309 proceeded to impute the remaining pixels with fewer condition constraints and fewer bins. 310 Clearly, if an area was imputed earlier in iteration, the imputation result was intrinsically more 311 accurate because the area is more similar to the plots falling within the area. During this 312 iteration, intensified plots serve an important role: the intensification was done in a way that 313 all the environment variables were considered and the remote sensing value was very close, 314 thereby assuring the pixels were "extremely similar". If there was no plot intensification, there 315 might be no sufficient suitable plots for a group to be imputed in an earlier iteration stage; 316 therefore, the intensification allows a group without sufficient actual FIA plots to be 317 associated with sufficient intensified plots to improve the imputation. 
319 If there were still insufficient plots falling within the group, we finished all remaining pixels

320 through three steps. First, we interpolated the missing value using a local window mean value

321 starting from a small window size $3 \times 3$ and gradually increasing the window size to $9 \times 9$.

322 Second, we divided the regression predicted SI map (i.e., Figure 5) into 20 bins and then

323 combined them with 52 climate zones (Figure 3a), 6 topography zones (Figure 3b), and 9

324 soil zones (Figure 3c), and 3 IBIS zones (Figure 3d), resulting in $20 \times 52 \times 6 \times 9 \times 3=168480$

325 strata. In each stratum, those pixels that had never been imputed were filled with the median

326 value of the already-imputed pixels that were within the same stratum. Third, these two

327 datasets (i.e., location interpolation and strata median) were averaged to fill the remaining

328 empty pixels.

329

\subsection{Accuracy assessment}

330 To evaluate the SI and MAI accuracy, we used 40 plots for accuracy assessment. Twenty of 331 these plots were the FIA plots that were withheld for validation; addition 20 plots were 332 surveyed in August 2016 specifically for the validation purpose with the FIA protocol (i.e., 333 selecting and boring the site trees) followed by the same SI and MAI determination. We 334 compared the field and estimated SI and MAI. The root-mean-square error (RMSE) (equation 335 5) and the mean absolute error (MAE) (equation 6) were computed as:

$336 \quad R M S E=\sqrt{\frac{\sum_{i=1}^{n}\left(y_{i}-\hat{y}_{i}\right)^{2}}{n}}$

$337 \quad M A E=\frac{\sum_{i=1}^{n}\left|\left(y_{i}-\hat{y}_{i}\right)\right|}{n}$

338 where $\mathrm{n}$ is equal to $40, y_{i}$ is field value, and $\hat{y}_{i}$ is prediction. 


\section{Results}

341 Site Index for TNF was produced from climate, topography, soil, Landsat, and FIA data

342 (Figure 6). The comparison between FIA field SI and predicted SI (Figure 7) shows that the 343 dots are distributed along line $1: 1$ and the $\mathrm{R}^{2}$ is 0.7637 with an RMSE of 3.60 and a MAE of 3443.07 meters, indicating that the $30 \mathrm{~m} \mathrm{SI}$ is accurate. Generally the low elevations on the west 345 side of the study area were characterized by high SI, indicating the good site quality in the 346 foothills and along the valley due to optimum moisture and temperatures for the associated 347 conifer species. In the high elevation Sierra crest (central portion of the TNF), the SI was 348 frequently low, indicating the poor site quality of mountain tops from their shallow soils. 349 Moving east of the Sierra crest increased SI as elevation decreased, but generally didn't reach 350 west side SI values due to more xeric conditions. However, on the east side, there was a 351 relatively lower elevation area (compared to surrounding high mountains, see Figure 1), 352 where the SI was unexpectedly high when compared to neighboring areas of similar 353 bioclimatic conditions. Further investigation revealed that there was a congregation of plots 354 that were within an intensively managed (fertilized, terraced, multiple herbicide applications) 355 plantation that most likely inflated surrounding SI values.

358 We calculated SI mean in different ecological zones (Table 3). When the elevation was lower than 700 900 m, the mean regional site index (RSI) was around 25 26, indicating that trees 
360

361

362

363

364

365

366

367 368 369

370

371

373

374 375

may grow up to $25 \sim 26 \mathrm{~m}$ at the age of 50 years without competition. However, when the elevation was above $700 \sim 900 \mathrm{~m}$, the SI consistently decreased from 24 to 11 , implying that elevation plays an important role in tree growth. For topography in terms of ridge, canyon, and slope, the SI ranged from 17 to 20 without obvious difference, indicating that influence of aspect and slope on SI was negligible or that their influence was overwhelmed by elevation change. For soil productivity, the SI was generally lower in the poor areas (ranking 1 4) but higher in the good areas (ranking 5 9) with an exception (SI was 17 in the area ranking 6). This indicates soil productivity had an effect on tree growth, but a consistent trend could not be observed.

\section{Insert table 3 around here}

A similar approach was used to produce the MAI map (Figure 8). The comparison between field and predicted MAI (Figure 9) shows the dots are generally distributed along line 1:1. The regression equation is $y=0.9592 x$ with an $R^{2}$ of 0.6882 , an RMSE of 1.73 , and a MAE of 1.20 cubic meters per hectare per year. These results indicate the $30 \mathrm{~m}$ MAI was $4.1 \%$ underestimated, but the accuracy was satisfactory. Several interesting patterns can be observed. First, the lower elevation west side of the study area was generally characterized by high MAI with a pattern similar to SI, indicating the high timber productivity in the foothills and along the valley. Second, in the high elevation Sierra crest, despite the low SI (around 6 15, see Figure 6), most of the MAI was not low, especially in the northern portion. The main reason was that the forest types were mainly California red fir, white fir, and California mixed conifer (see Figure 2 for the forest distribution), and their MAI was relatively high when the SI was 6 15 (see Figure 10, which is another expression form of Table 1). Third, in the east side of the study area, the SI was relatively high (around 24 37, see Figure 6); 
383 however, the MAI was low (around $4 \sim 8$ cubic meters per hectare per year, see Figure 8). The 384 main reason was that the forest types were ponderosa pine and Jeffrey pine (see Figure 2 for 385 the forest distribution), and their MAI was relatively low when the SI was 24 37 (see Figure 386 10). These indicate that timber productivity is related to site quality, and forest type plays an 387 important role as well.

388

389

390

391

392

393

394

395 396
Insert figure 8 around here

Insert figure 9 around here

Insert figure 10 around here

\section{Discussion}

In this study, we used a new approach to produce the SI and MAI maps. This method is a nonparametric approach independent of data assumptions. This method can reduce the influence of plot location errors. It can also address the potential issue of insufficient plots. However, this method has two disadvantages that are related to SI and MAI mapping.

First, the method requires that field plots are a representative sample of the landscape, which means the SI and MAI from field measurements need to be collected in different areas to capture the heterogeneity. This was also the reason why we chose 205 of 225 plots to create maps: we wanted the training plots to cover the landscape and its inherent heterogeneity. Nevertheless, SI is species dependent and must be calculated by species. If the species of interest can only be found in a limited extent (e.g., site trees of California red fir were not

found in the west side of our study area, as shown in Figure 1), then the prerequisite of 
"representativeness" is broken, which creates a barrier to producing a continuous SI map over a large area. Although SI value is not usually equivalent between species, some relationship exists among species: the adjustment factors $\left(F_{s}\right)$ as shown in Table $\mathbf{2}$ can be used to convert different species into a common reference. It should be pointed out that species-specific site indices can then be obtained by multiplying the regional SI (as shown in Figure 6) and their corresponding adjustment factor (as shown in Table 2), which can provide useful information for species management. If our approach is applied to other regions that are heterogeneous in terms of environment and tree species, the adjustment factors for additional species may need to be found in order to complete a regional mapping effort.

Second, the method needs to select the variables that significantly correlate with SI and MAI for imputation. There are typically a large number of readily available covariates in the form of remotely sensed and geospatial data. Many previous studies (e.g., Mohamed et al., 2014; Sabatia and Burkhart, 2014) chose the variables related to topography (elevation, aspect, and slope), soil ( $\mathrm{pH}$, sand, and silt), and climate (temperature and precipitation zones) as the major determining factors of SI and MAI. In this study, we selected AET, CWD, $\mathrm{T}_{\mathrm{jul}}, \mathrm{T}_{\mathrm{jan}}$, topography, and soil for imputation. Additionally, we adopted Landsat remote sensing for imputation. As expected, the correlation between Landsat pixel metrics and SI of FIA plots is low. However, Landsat uses an optical sensor that captures the plant spectrum features, which are not a directly determining factor of SI and MAI. Nevertheless, land surface, especially vegetation distribution, is a result of the combined effect of the determining factors such as climate, soil, and moisture. Landsat imagery is sensitive to chlorophyll which can indicate prevailing conditions in the forest site, and the amount of chlorophyll is closely related to forest growth and plant spectrum traits (Ma et al., 2006; Ung et al., 2001); therefore, Landsat 
427 reflectance was used in our study. The $30 \mathrm{~m}$ Landsat allowed us to map SI and MAI at $30 \mathrm{~m}$,

428 which cannot be accomplished with the climate, soil, and topography alone at coarser 429 resolution.

430 In addition to the quantitative validation from 40 plots, the $30 \mathrm{~m} \mathrm{SI}$ and MAI products that we 431 created were also qualitatively evaluated by local foresters having intimate knowledge of the 432 landscape. Their feedback showed our products were very promising and deemed important 433 for local forest management in the TNF regarding fuels management to reduce fire severity, 434 plantation, biodiversity, and carbon. For fuels management, local managers use these products 435 to understand where fuels accumulate the fastest which could then target those areas for 436 potential fuel reduction. For plantation, our products are used to locate the optimal site and 437 species combinations for tree planting to aid post-fire ecosystem recovery. For biodiversity, 438 the TNF is about to embark on its forest plan revision where part of that plan is to manage the 439 California Spotted Owl (Strix occidentalis occidentalis). Wildlife biologists use SI and MAI 440 to locate those more mesic areas that can sustain more trees around Owl nests for retention 441 and those more xeric environments for potential tree density management. For carbon 442 sequestration, local managers can use SI and MAI to identify the poor and productive areas to 443 make decisions related to carbon cap-and-trade and carbon taxes. More potential applications 444 are currently being explored to take full advantage of the high-resolution SI and MAI products.

445 The products created from this study were produced with an automated tool (Huang et al., 446 2016). Three research directions are warranted. First, in our current study, we used limited 20 447 FIA plots plus extra 20 plots for validation; however, cross-validation may be preferred for a 448 more convincing accuracy assessment. Second, our method is a nonparametric approach 449 similar to the nearest neighbor method. The only assumption is that the explanatory variables 
450 (e.g., climate) have a strong relationship to the response variable (e.g., SI); a complete 451 knowledge of the complicated relationships between them is not needed (Eskelson et al., 452 2009). When the number of explanatory variables increases, selecting the critical and 453 important variables for forest attributes prediction is a challenging and time-consuming task, 454 which still remains daunting for the widely-used nearest neighbor approach (McRoberts, 2012; 455 Brosofske at al., 2014). Stepwise regression analysis, correlation analysis, neural network, 456 and feature extraction approaches may be used to identify the suitable variables (Lu, 2006). 457 We have incorporated the stepwise regression (e.g., equation 2) into an automation line of 458 FastEmap to aid variable selection (Huang et al., 2016); however, stepwise model selection 459 has deficiencies (Flom and Cassell, 2007). Therefore, in our study on SI and MAI, we 460 identified the variables and their importance based on additional expert judgement, which 461 plays an important role in landscape ecology (Perera et al., 2012). The number of explanatory 462 variables for SI and MAI in our study was limited (i.e., only Landsat bands, 463 climate/topography/soil zones, and IBIS productivity). When our method is applied to future 464 studies and there are many variables to choose from, the procedure of selecting the critical and 465 important variables still needs to be automated somehow. Third, the present study was 466 conducted only in TNF. With the availability of SI and MAI in the FIA database, the next step 467 is to apply the methodology to a broader area (e.g., entire California) so that 30m SI and MAI 468 maps can be accessed by the public without releasing the actual plot locations.

\section{Conclusion}


471 Over a heterogeneous mountain, the U.S. FIA program has been collecting point-specific site 472 index (SI), but SI is species-specific and a tree species may be only found in a limited extent, 473 so directly putting different species site indices together to predict continuous SI is not 474 feasible. However, a relationship exists among different species, which can lead to a 475 conversion by an adjustment factor so that all species can be simultaneously combined for SI 476 mapping. This adjustment factor could be used to convert different species site indices into a 477 region SI, a common reference independent upon site tree species.

478 In extrapolating point-specific SI data to a heterogeneous TNF, the common stepwise 479 regression approach could capture the general distribution pattern of SI, but the accuracy (with 480 a low $R^{2}$ of 0.29 ) was not sufficiently satisfactory. Our new approach consists of four major 481 modules "intensifying", "regression", "imputation" and "filling". The 4-step methodology 482 resulted in an improved SI prediction, with an $\mathrm{R}^{2}$ of 0.7637 , an RMSE of 3.60, and a MAE of $483 \quad 3.07$ meters. Plot-level MAI could be modelled from FIA site index and could be similarly 484 extrapolated to landscape level at 30m resolution using the same 4-step approach, resulting in 485 a MAI map with an $\mathrm{R}^{2}$ of 0.6882 , an RMSE of 1.73 , and a MAE of 1.20 cubic meters per 486 hectare per year. These SI and MAI results indicate our new approach is effective enough to 487 map SI and MAI at 30m resolution over a complex landscape. The SI and MAI maps can be 488 applied to fire, plantation, biodiversity, and carbon management. 
492 We thank Kurt Campbell at U.S. Forest Service Pacific Northwest Research Station for 493 helping with mean annual increment modeling and Miss Christine Chu for improving the 494 English. This work was supported by the United States Department of Agriculture. Any use of 495 trade, product, or firm names is for descriptive purposes only and does not imply endorsement 496 by the US Government.

497 


\section{$498 \quad$ References}

499 Beaulieu, J., Raulier, F., Pregent, G., and Bousquet, J., 2011. Predicting site index from 500 climatic, edaphic, and stand structural properties for seven plantation grown conifer species 501 in Quebec. Canadian Journal of Forest Research, 41(4): 682-693. doi:10.1139/x11-006.

502 Brandl, S., Falk, W., Klemmt, H., Stricker, G., Bender, A., Rötzer, T., and Hans Pretzsch, 503 2014. Possibilities and Limitations of Spatially Explicit Site Index Modelling for Spruce 504 Based on National Forest Inventory Data and Digital Maps of Soil and Climate in Bavaria 505 (SE Germany). Forests, 5, 2626-2646; doi:10.3390/f5112626

506 Breidenbach, J., Næsset, E., and Gobakken, T., 2012. Improving k-nearest neighbor 507 predictions in forest inventories by combining high and low density airborne laser scanning 508 data. Remote Sensing of Environment, 117, 358-365.

509 Breiman, L., 2001. Random Forests. Machine Learning, 45(1): 5-32

510
Brickell, J.E., 1970. Equations and computer subroutines for estimating site quality of eight Rocky Mountain species. Res. Pap. INT-75. Ogden, UT: Intermountain Forest and Range Experiment Station. 22 p.

Brosofske, K.D., Froese, R.E., Falkowski, M. J., and Banskota, A., 2014. A review of methods for mapping and prediction of inventory attributes for operational forest management. Forest Science, 60(4), 733-756.

Coops, N.C., Gaulton, R., and Waring, R.H., 2011. Mapping site indices for five Pacific Northwest conifers using a physiologically based model. Applied Vegetation Science, 14, $268-276$ 
519 Crookston, N.L., Rehfeldt, G.E., Dixon, G.E., and Weiskittel, A.R., 2010. Addressing climate 520 change in the forest vegetation simulator to assess impacts on landscape forest dynamics. 521 Forest Ecology and Management, 260, 1198-1211.

522 Curt, T., Bouchaud, M., and Agrech, G., 2001. Predicting site index of Douglas-fir plantations 523 from ecological variables In the Massif central area of France. Forest Ecology and 524 Management, 149: 61-74

525 Dahms, W.G., 1975. Gross yield of central Oregon lodgepole pine. In: Baumgartner, D. M., 526 ed. Management of lodgepole pine ecosystems symposium proceedings. Pullman, WA: 527 Washington State University Cooperative Extension Service. 25 p.

528 Dunning, D., and Reineke, L.H., 1933. Preliminary yield tables for second-growth stands in 529 the California pine region. Tech. Bull. 354. Washington, DC: U.S. Department of $530 \quad$ Agriculture. $24 \mathrm{p}$.

531 Eskelson, B.N.I., Temesgen, H., Lemay, V., Barrett, T.M., Crookston, N.L., and Hudak, A.T., 532 2009. The roles of nearest neighbor methods in imputing missing data in forest inventory 533 and monitoring databases. Scandinavian Journal of Forest Research, 24(3): 235-246.

534 Falkowski, M.J., Wulder, M.A., White, J.C., and Gillis, M.D., 2009. Supporting large-area, 535 sample-based forest inventories with very high spatial resolution satellite imagery. Progress 536 in Physical Geography, 33, 403-423.

537 Flint, L.E., Flint, A.L., Thorne, J.H., and Boynton, R., 2013. Fine-scale hydrologic modeling 538 for regional landscape applications: the California Basin Characterization Model 
539 development and performance. Ecological Processes 2:25. Available online at: $540 \quad \mathrm{http}: / / \mathrm{www}$. ecologicalprocesses.com/content/2/1/25

541 Foley, J.A., Colin, P.I., Ramankutty, N., Levis, S., Pollard, D., Sitch, S., and Haxeltine, A., 542 1996. An integrated biosphere model of land surface processes, terrestrial carbon balance, 543 and vegetation dynamics. Global Biogeochemical Cycles, 10, 603-628.

544 Flom, P.L. and Cassell, D.L., 2007. Stopping stepwise: Why stepwise and similar selection 545 methods are bad, and what you should use. NorthEast SAS Users Group (NESUG 2007) $546 \quad$ proceedings

547 Fries, A., Lindgren, D., Ying, C.C., Ruotsalainen, S., Lindgren, K., Elfving, B., and Karlmats, 548 U., 2000. The effect of temperature on site index in western Canada and Scandinavia 549 estimated from IUFRO Pinus contorta provenance experiments. Canadian Journal of Forest $550 \quad$ Research, 30, 921-929.

551 Hamel, B.T., Bélanger, N., and Paré, D., 2004. Productivity of black spruce and Jack pine 552 stands in Quebec as related to climate, site biological features and soil properties. Forest $553 \quad$ Ecology and Management, 191, 239-251.

554 Huang, S., Ramirez, C., Kennedy, K., Mallory, J., 2016. A new approach to extrapolate forest 555 attributes from field inventory with satellite and auxiliary datasets. Forest Science, in press.

556 Jiang, H., Radtke, P.J., Weiskittel, A.R., Coulston, J.W., and Guertin, P.J., 2015. Climate- and 557 soil-based models of site productivity in eastern US tree species. Canadian Journal of $558 \quad$ Forest Research, 45: 325-342, dx.doi.org/10.1139/cjfr-2014-0054 
559 Keyser, C.E., Dixon, G.E., comp. 2008 (revised November 2, 2015). Western Sierra Nevada 560 (WS) Variant Overview - Forest Vegetation Simulator. Internal Rep. Fort Collins, CO: U. 561 S. Department of Agriculture, Forest Service, Forest Management Service Center. 82p.

562 Krumland, B., 2004. CMIA in California Based on New Site Index Models (unpublished)

563 Kucharik, C. J., Foley, J. A., Delire, C., Fisher, V. A., Coe, M. T., Lenters, J. D., Young564 Molling, C., Ramankutty, N., Norman, J. M., and Gower, S. T., 2000. Testing the 565 performance of a dynamic global ecosystem model: Water balance, carbon balance, and 566 vegetation structure, Global Biogeochem. Cycles, 14(3), 795-825.

567 Latta, G., Temesgen, H., and Barrett, T.M., 2009. Mapping and imputing potential 568 productivity of Pacific Northwest forests using climate variables. Canadian Journal of $569 \quad$ Forest Research, 39(6), 1197-1207, 10.1139/X09-046

570

571

Lu, D., 2006. The potential and challenge of remote sensing - based biomass estimation. International Journal of Remote Sensing, 27(7), 1297-1328.

Ma M., Jiang H., Liu S., Zhu C., Liu Y., and Wang J., 2006. Estimation of forest-ecosystem site index using remote sensed data. Acta Ecologica Sinica, 2006, 26(9), 2810-2816.

Masek, J. G., Vermote, E. F., Saleous, N. E., Wolfe, R., Hall, F. G., Huemmrich, K. F., Gao,F., Kutler, J., and Lim, T. K., 2006. A Landsat surface reflectance dataset for North America, 1990-2000. IEEE Geoscience and Remote Sensing Letters, 3(1), 68-72.

McArdle, R.E., Meyer, W.H., Bruce, D., 1961. The yield of Douglas fir in the Pacific Northwest. 2nd rev. Tech. Bull. 201. Washington, DC: U.S. Department of Agriculture. 65 p. 
580 McRoberts, R.E., Holden, G.R., Nelson, M.D., Liknes, G.C., Moser, W.K., Lister, A.J., King, 581 S.L., LaPoint, E.B., Coulston, J.W., Smith, W.B., and Reams, G.A., 2005. Estimating and 582 circumventing the effects of perturbing and swapping inventory plot locations. Journal of $583 \quad$ Forestry, 103(6), 275-279.

584 McRoberts, R.E., 2008. Using satellite imagery and the k-nearest neighbors technique as a 585 bridge between strategic and management forest inventories. Remote Sensing of $586 \quad$ Environment, 112, 2212-2221.

587 McRoberts, R.E. 2010. The effects of rectification and global positioning system errors on 588 satellite image-based estimates of forest area. Remote Sensing of Environment, 114, 1710 $589-1717$.

590 McRoberts, R.E., 2012. Estimating forest attribute parameters for small areas using nearest 591 neighbors techniques. Forest Ecology and Management, 272:3-12.

592 Meyer, W.H., 1961. Yield of even-aged stands of ponderosa pine. Rev. Tech. Bull. 630.

593 Mohamed, A., Reich, R.M., Khosla, R., Aguirre-Bravo, C., and Briseño, M.M., 2014. 594 Influence of climatic conditions, topography and soil attributes on the spatial distribution of 595 site productivity index of the species rich forests of Jalisco, Mexico. Journal of Forestry $596 \quad$ Research, 25(1), 87-95

597 Monserud, R.A., Huang, S., and Yang, Y., 2006. Predicting lodgepole pine site index from 598 climatic parameters in Alberta. The Forestry Chronicle, 82, 562-571 
599 Muinonen, E., Maltamo, M., Hyppanen, H., \& Vainikainen, V. (2001). Forest stand 600 characteristics estimation using a most similar neighbor approach and image spatial 601 structure information. Remote Sensing of Environment, 78, 223-228

602 Nilsson, M. (1997). Estimation of forest variables using satellite image data and airborne 603 Lidar. PhD dissertation, Swedish University of Agricultural Sciences, Umea ${ }^{\circ}$, Sweden.

604 North, M. (ed.), 2012. Managing Sierra Nevada forests. Gen. Tech. Rep. PSW-GTR-237. 605 Albany, CA: U.S. Department of Agriculture, Forest Service, Pacific Southwest Research $606 \quad$ Station. 184 p.

607 Perera, A.H., Drew,C.A., and Johnson, C.J. (eds.), 2012. Expert knowledge and its application 608 in landscape ecology. Springer, New York, USA, 307 pp.

609 Nothdurft, A., Wolf, T., Ringeler, A., Böhner, J., and Saborowski, J., 2012. Spatio-temporal 610 prediction of site index based on forest inventories and climate change scenarios. Forest 611 Ecology and Management, 279, 97-111. doi:10.1016/j.foreco.2012.05.018.

612 Sabatia, C.O., and Burkhart, H.E., 2014. Predicting site index of plantation loblolly pine from 613 biophysical Variables. Forest Ecology and Management, 326, 142-156

614 Schumacher, F.X., 1928. Yield, stand and volume tables for red fir in California. Exp. Station 615 Bull. 456. Berkeley, CA: University of California Experiment Station. 29 p.

616 Sharma, R.P., Brunner, A., and Eid, T., 2012. Site index prediction from site and climate 617 variables for Norway spruce and Scots pine in Norway. Scandinavian Journal of Forest $618 \quad$ Research, 27, 619-636. 
619 Swenson, J.J., Waring, R.H., Fan, W., and Coops,N., 2005. Predicting site index with a 620 physiologically based growth model across Oregon, USA. Canadian Journal of Forest $621 \quad$ Research, 35, 1696-1707.

622 Ung, C.-H., Bernier, P.Y., Raulier, F., Fournier, R.A., Lambert, M. C., and Régnière, J., 2001. 623 Biophysical site indices for shade tolerant and intolerant boreal species. Forest Science, $624 \quad 47(1): 83-95$.

625 Wang, G.G., and Klinka, K., 1996. Use of synoptic variables in predicting white spruce site 626 index. Forest Ecology and Management, 80, 95-105.

627 Waring, R. H., Milner, K. S., Jolly, W. M., Phillips, L., and McWethy, D., 2006. Assessment 628 of site index and forest growth capacity across the Pacific and Inland Northwest U.S.A. 629 with a MODIS satellite-derived vegetation index. Forest Ecology and Management, 228, $630 \quad 285-291$.

631 Weiskittel, A.R., Crookston, N.L., and Radtke, P.J., 2011. Linking climate, gross primary 632 productivity, and site index across forests of the western United States. Canadian Journal of 633 Forest Research, 41, 1710-1721.

634 Worthington, N.P., Johnson, F.A., Staebler, G.R., and Lloyd, W.J., 1960. Normal yield tables 635 for red alder. Res. Pap. 36. Portland, OR: U.S. Department of Agriculture, Forest Service, 636 Pacific Northwest Forest and Range Experiment Station. 3 p. (plus tables). 


\section{Tables}

639 Table 1. Mean annual increment (MAI, in cubic meters per hectare per year) calculation for 640 forest type

\section{Forest type}

MAI Equation*

References

(COND_FORTYPCD code)

\begin{tabular}{ll}
\hline Douglas-fir forest (201) & $-4.20+0.39 \times$ SI $(\mathrm{SI}<22.86)$ \\
& $-5.69+0.46 \times$ SI $(22.86<=\mathrm{SI}<=39.62)$ \\
& $1.60+0.28 \times \mathrm{SI}(\mathrm{SI}>39.62)$
\end{tabular}

California red fir forest (262)

$3.38+0.017 \times \operatorname{pow}(\mathrm{SI} \times 3.28,1.6)$

Schumacher (1928)

White fir forest (261)

$0.0088 \times \operatorname{pow}(\mathrm{SI} \times 3.28,1.561)+1.66$

Krumland (2004)

Ponderosa pine forest (221)

$\exp (0.702695 \times \operatorname{pow}(\mathrm{SI} \times 3.28,0.42)-$

Meyer (1961)

$0.51367) \times 0.070$

Jeffrey pine forest (225)

$\exp (0.702695 \times \operatorname{pow}(\mathrm{SI} \times 3.28,0.42)$

Meyer (1961)

$0.51367) \times 0.070$

Western white pine forest $(241) \quad 1.04+0.40 \times$ SI

Brickell (1970)

Lodgepole pine forest (281)

$0.20 \times \mathrm{SI}-1.56$

Dahms (1975)

California mixed conifer (371)

$\exp (0.578265 \times \operatorname{pow}(\mathrm{SI} \times 3.28,0.4)+$

Dunning and Reineke (1933)

$$
1.8108) \times 0.70
$$

Hardwoods forest

$$
0.39 \times \mathrm{SI}-3.72
$$

Worthington et al. (1960)

$(922,931,933,962)$

* exp is natural exponent and pow is power function; the equations were revised from original

642 equations due to the unit difference; SI is in unit of meters with reference age of 50 years;

643 MAI is in unit of cubic meters per hectare per year.

644 
645 Table 2. Site tree species and the adjustment factor

\begin{tabular}{lll}
\hline $\begin{array}{l}\text { Site tree common name } \\
\text { (SITE_SPCD) }\end{array}$ & Scientific name & $\mathbf{F}_{\mathbf{s}}$ \\
\hline Douglas-fir (202) & Pseudotsuga menziesii & 1.0 \\
California red fir (20) & Abies magnifica & 1.0 \\
White fir (15) & Abies concolor & 1.0 \\
Ponderosa pine (122) & Pinus ponderosa & 1.0 \\
Jeffrey pine (116) & Pinus Jeffreyi & 1.0 \\
Sugar pine (117) & Pinus lambertiana & 0.9 \\
\hline
\end{tabular}

646

647 
648 Table 3. Mean regional site index (RSI) in elevation, topography, and soil productivity zones

\begin{tabular}{|c|c|c|c|c|c|}
\hline \multicolumn{4}{|l|}{ Elevation } & \multicolumn{2}{|l|}{ Soil } \\
\hline (m) & RSI & Topography & RSI & productivity* & RSI \\
\hline$<500$ & 26 & Ridge & 18 & Rank 1 & 18 \\
\hline $500-700$ & 25 & Canyon/drainage & 19 & Rank 2 & 17 \\
\hline $700-900$ & 26 & Middle slope northeast $<30 \%$ slope & 18 & Rank 3 & 17 \\
\hline $900-1100$ & 24 & Middle slope northeast $>30 \%$ slope & 17 & Rank 4 & 17 \\
\hline $1100-1300$ & 24 & Middle slope southwest $<30 \%$ slope & 20 & Rank 5 & 22 \\
\hline $1300-1500$ & 22 & Middle slope southwest $>30 \%$ slope & 18 & Rank 6 & 17 \\
\hline $1500-1700$ & 20 & & & Rank 7 & 27 \\
\hline $1700-1900$ & 18 & & & Rank 8 & 21 \\
\hline $1900-2100$ & 15 & & & Rank 9 & 24 \\
\hline $2100-2300$ & 13 & & & & \\
\hline $2300-2500$ & 11 & & & & \\
\hline$>2500$ & 11 & & & & \\
\hline
\end{tabular}




\section{Figure captions}

652 Figure 1. Study area of Tahoe National Forest in California, USA encircled by the white 653 polygon. The background is a Digital Elevation Model (DEM) ranging from 200m in black 654 to $2800 \mathrm{~m}$ in white. Site index for different site tree species were surveyed in Forest 655 Inventory Analysis (FIA) plots. Note the plot locations were perturbed according to law 656 and this is for demonstration only.

657 Figure 2. The plot forest type determined by the Forest Inventory Analysis (FIA) program. 658 The background is a Landsat normalized difference vegetation index (NDVI) ranging from 659 660 0.3 (black) up to 0.9 (white). Note the plot locations were perturbed according to law and this is for demonstration only.

Figure 3. The map of 52 climate zones (a), 6 topography zones (b), 9 soil productivity zones (c), and continuous modeling productivity (d).

663 Figure 4. Flowchart and conceptual modeling framework of site index.

664 Figure 5. Regional site index (SI) map predicted from stepwise regression analysis.

665 Figure 6. Region site index (SI) prediction in the Tahoe National Forest.

666 Figure 7. The comparison between field and predicted site index from 40 validation plots.

667 Figure 8. Mean annual increment (MAI) prediction in the Tahoe National Forest.

668 Figure 9. The comparison between field and predicted mean annual increment (MAI) from 40 $669 \quad$ validation plots. 
670 Figure 10. Mean annual increment (MAI) prediction curve from site index (SI) for different 671 forest type. 


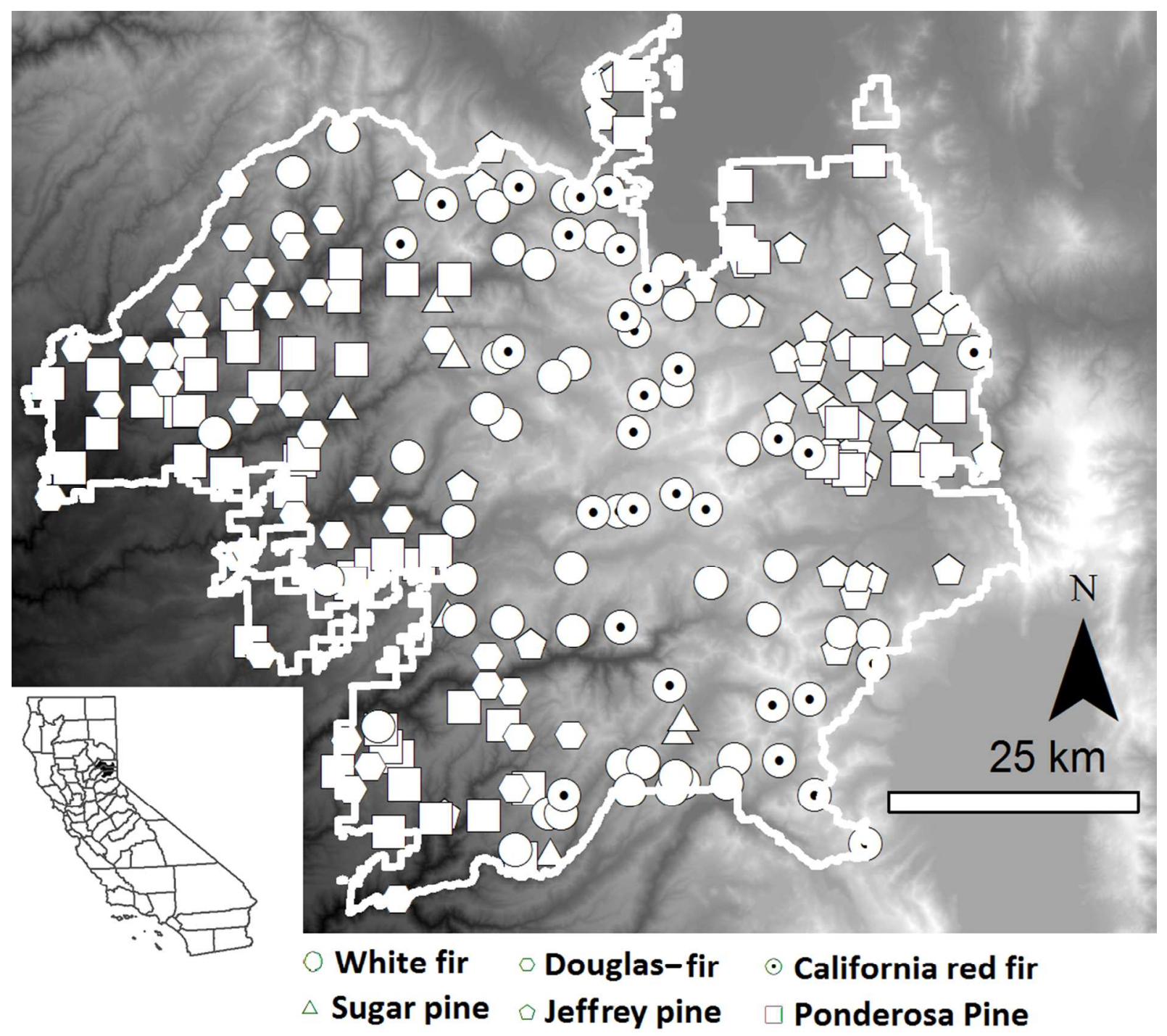

Figure 1. Study area of Tahoe National Forest in California, USA encircled by the white polygon. The background is a Digital Elevation Model (DEM) ranging from 200m in black to $2800 \mathrm{~m}$ in white. Site index for different site tree species were surveyed in Forest Inventory Analysis (FIA) plots. Note the plot locations were perturbed according to law and this is for demonstration only. 


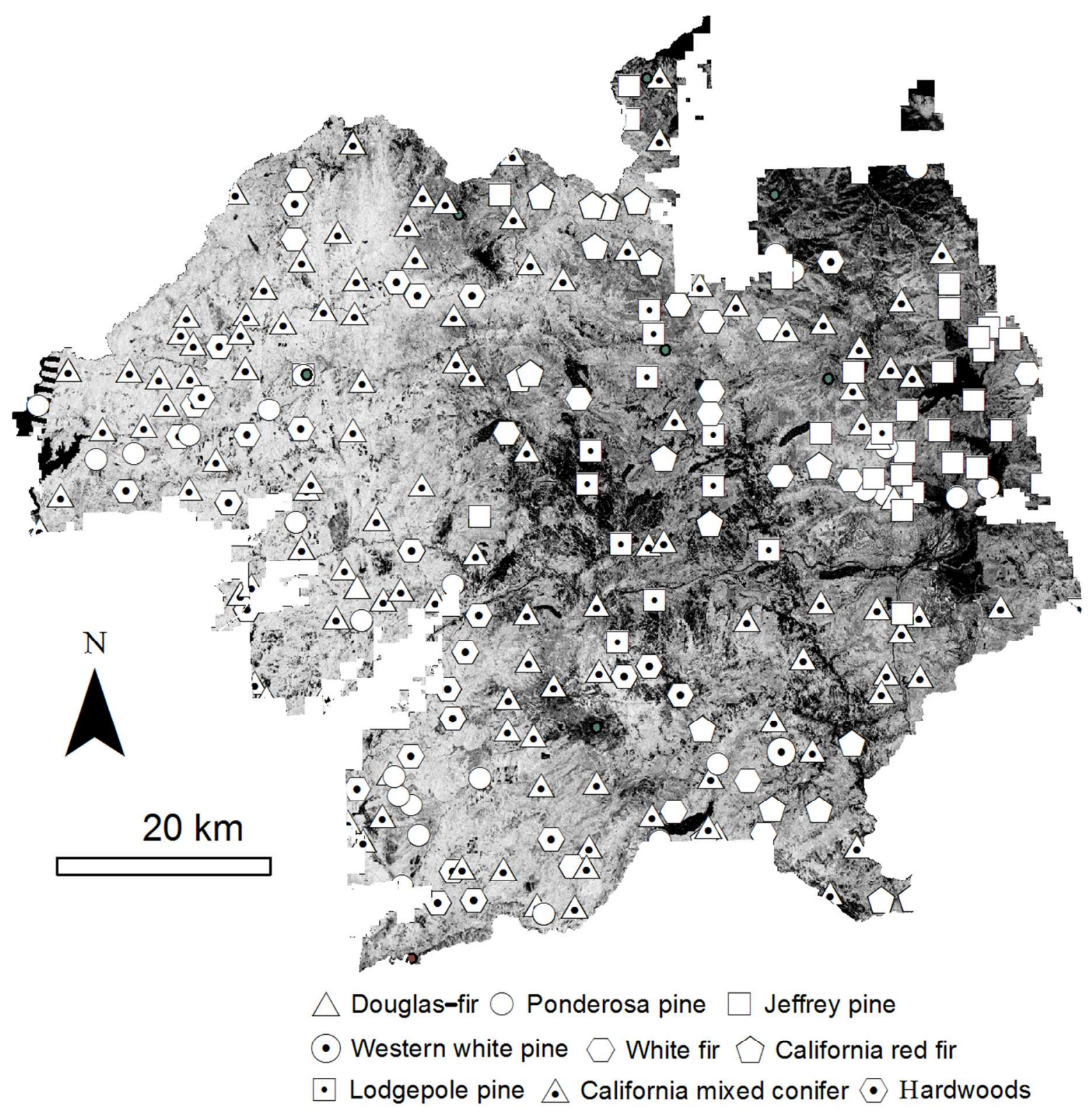

Figure 2. The plot forest type determined by the Forest Inventory Analysis (FIA) program. The background is a Landsat normalized difference vegetation index (NDVI) ranging from 0.3 (black) up to 0.9 (white). Note the plot locations were perturbed according to law and this is for demonstration only. 


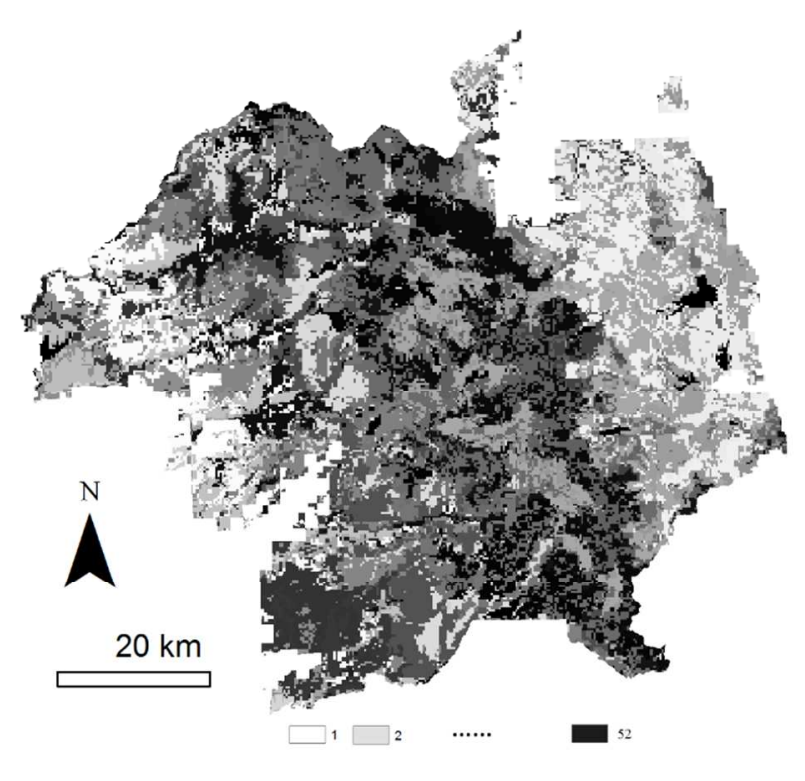

$\mathrm{a}$

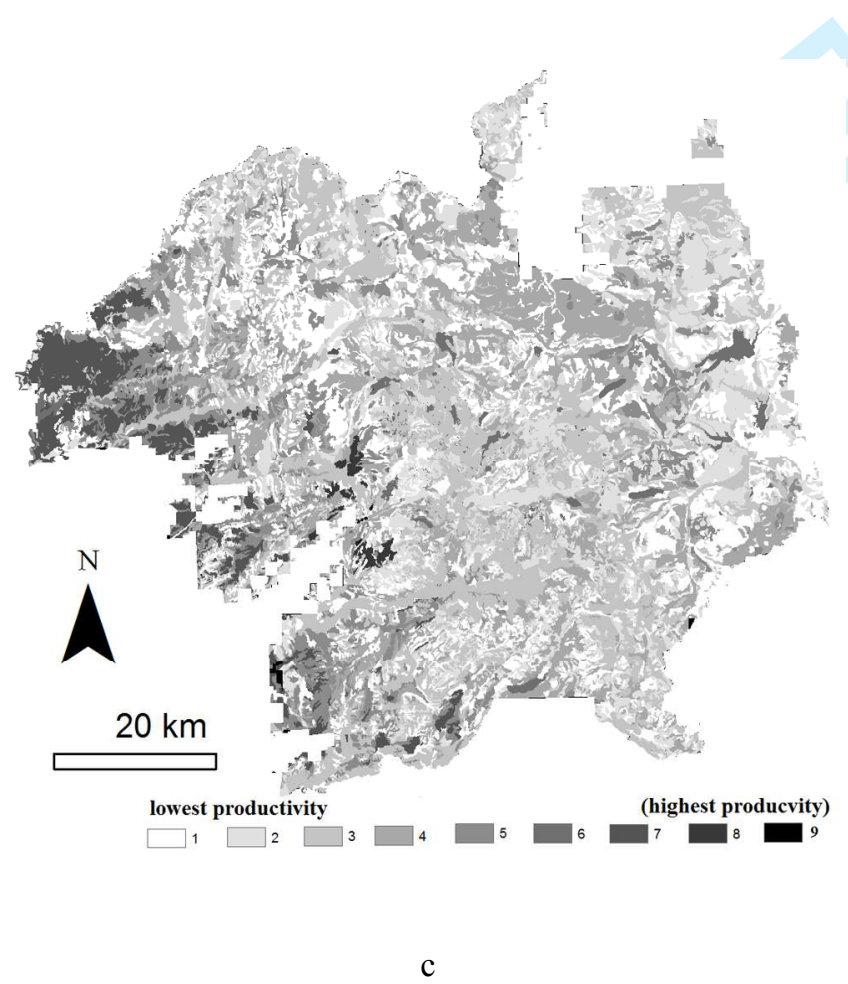

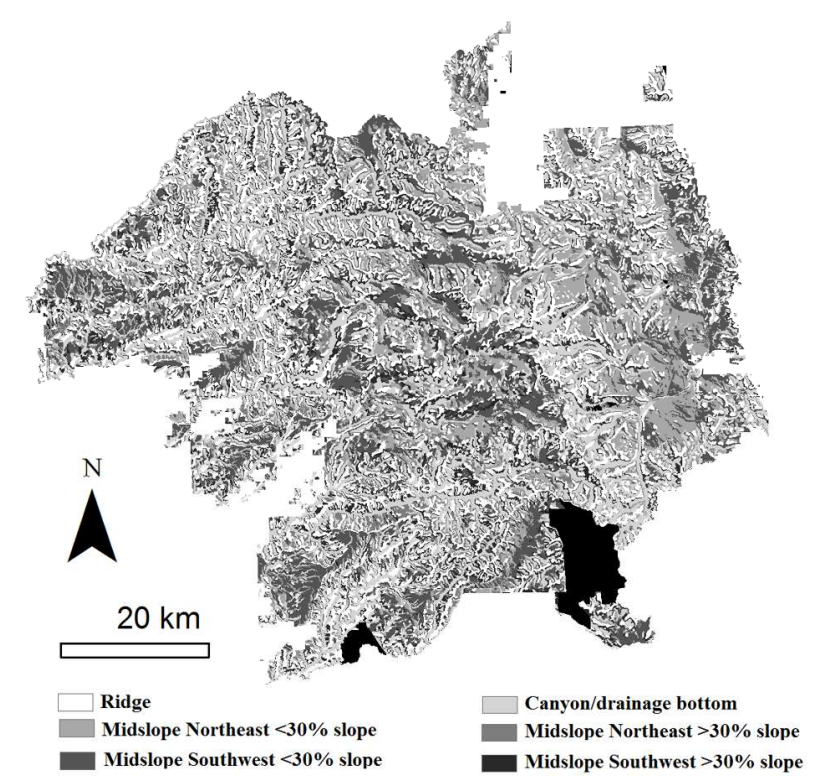

$\mathrm{b}$

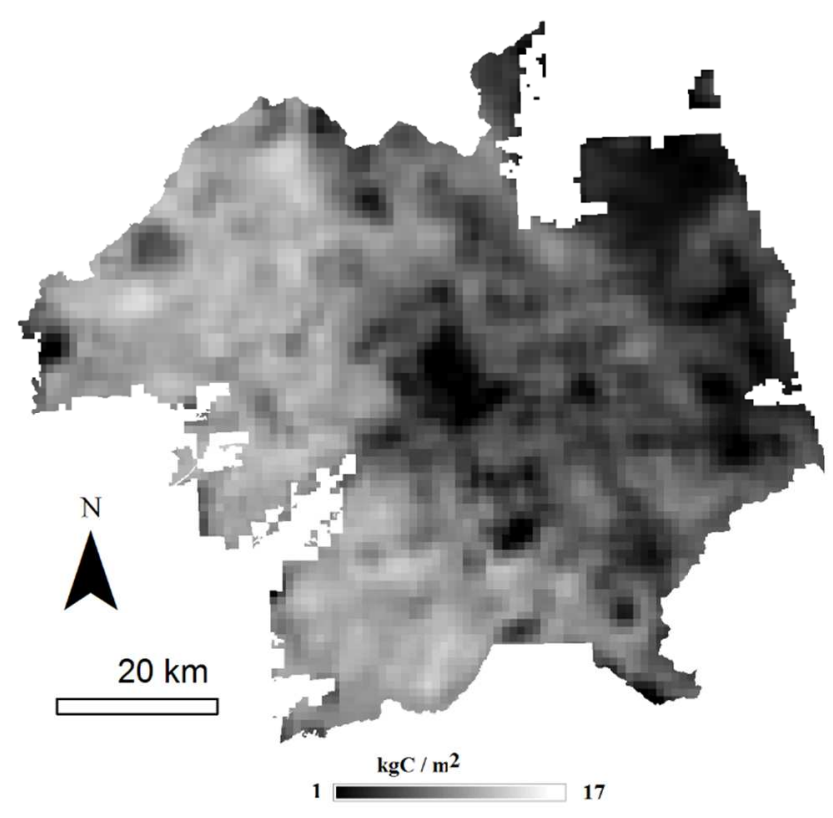

d

Figure 3. The map of 52 climate zones (a), 6 topography zones (b), 9 soil productivity zones (c), and continuous modeling productivity (d). 


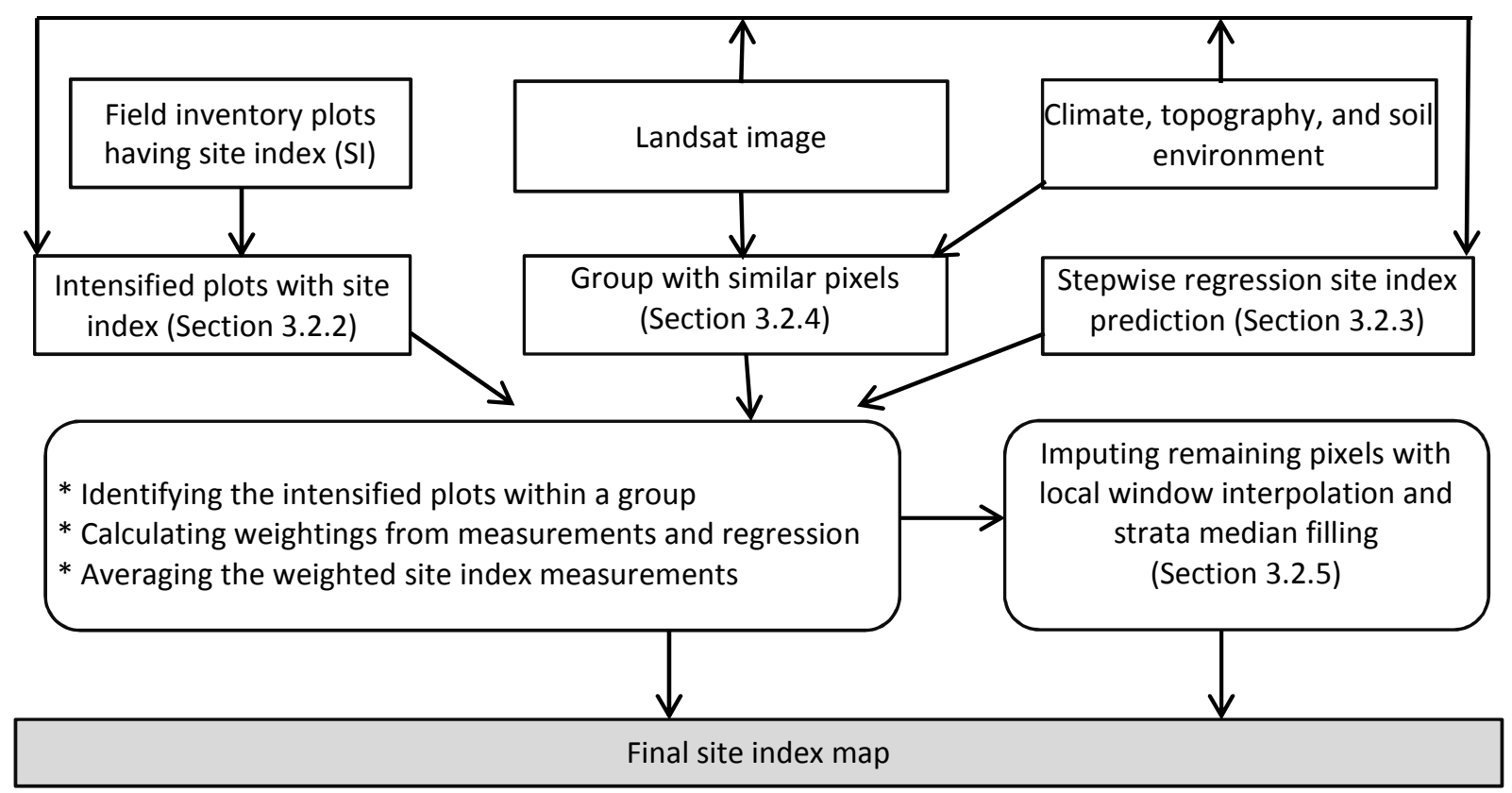

Figure 4. Flowchart and conceptual modeling framework of site index. 


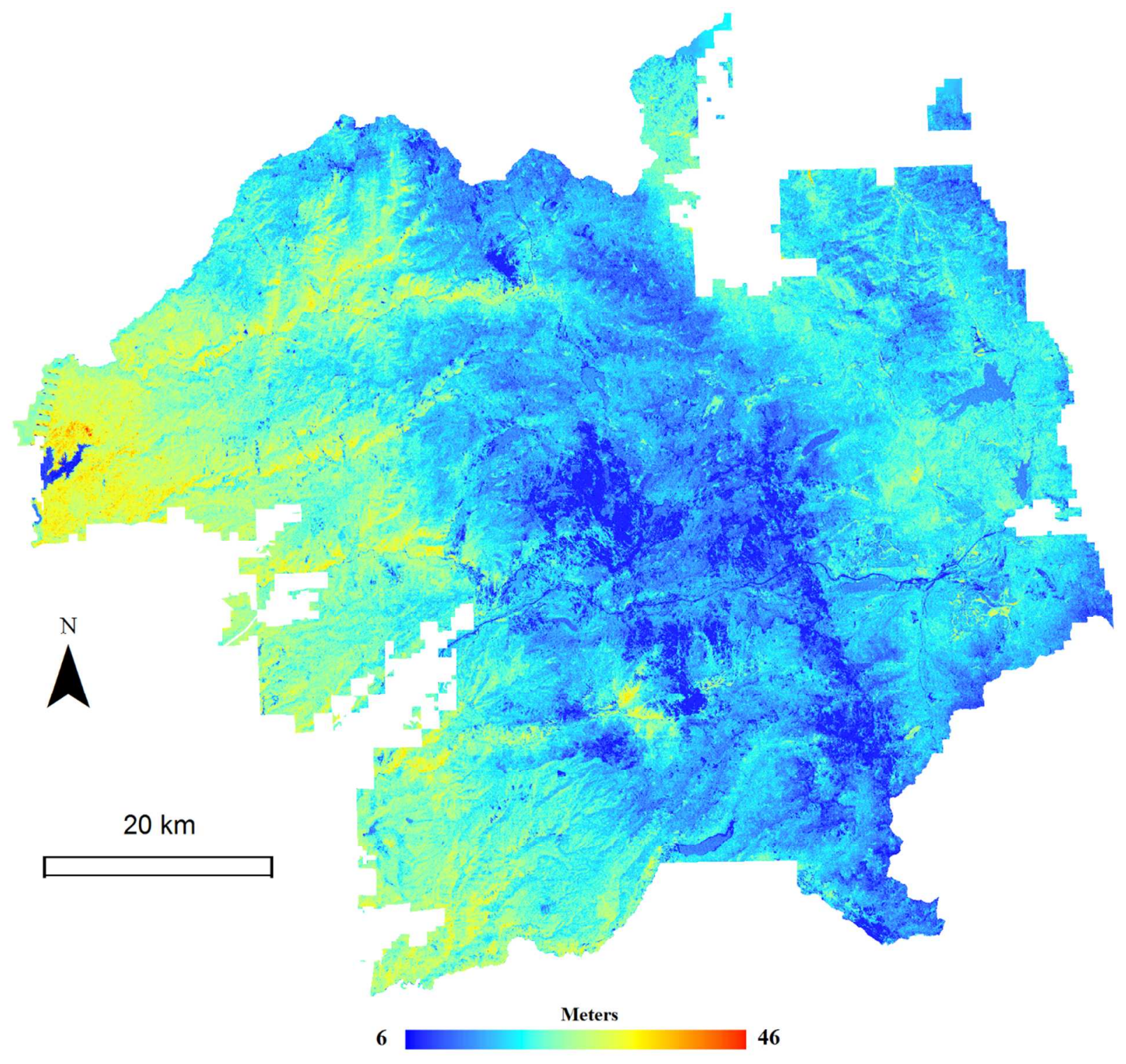

Figure 5. Regional site index (SI) map predicted from stepwise regression analysis 


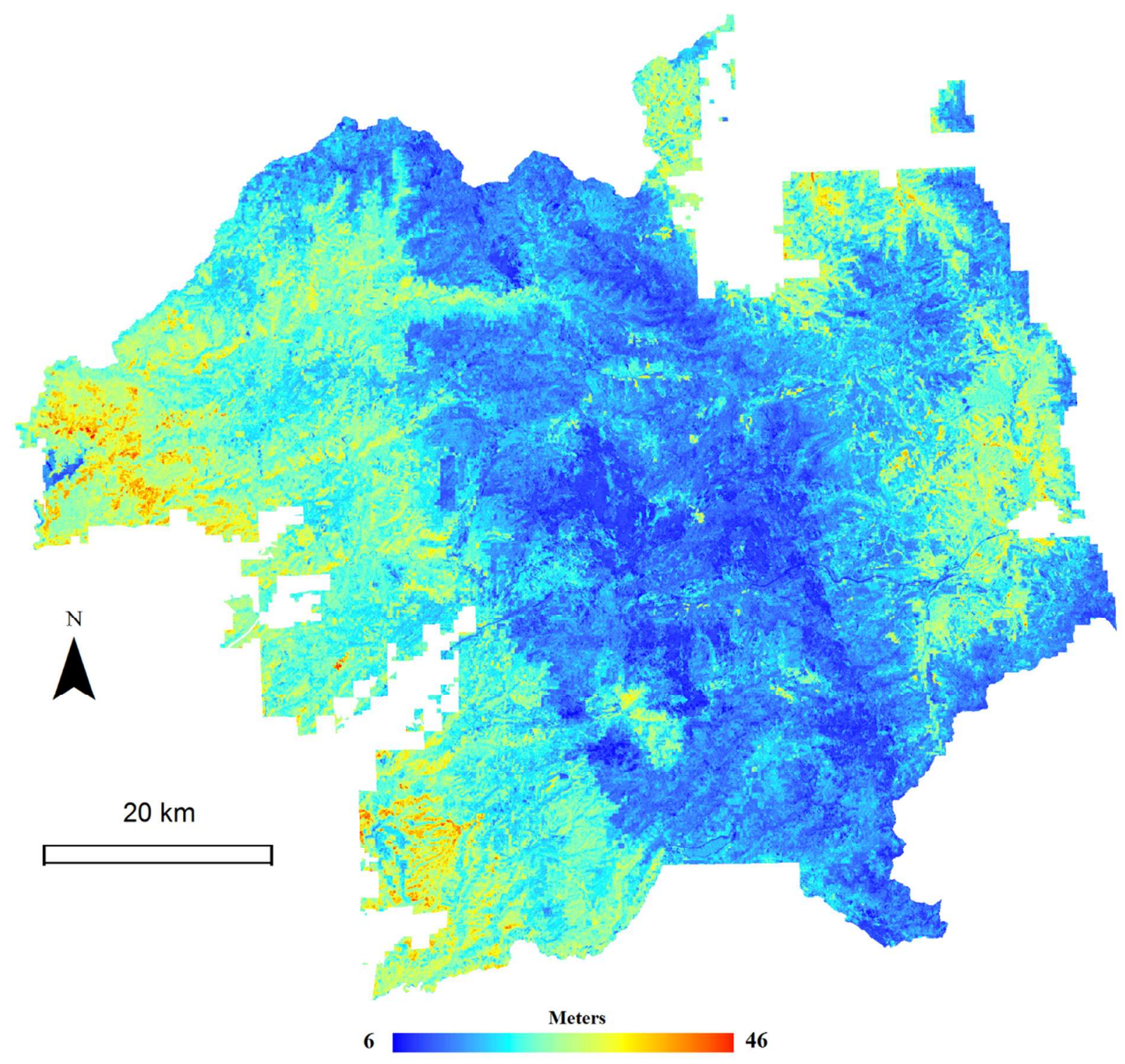

Figure 6. Region site index (SI) prediction in the Tahoe National Forest 


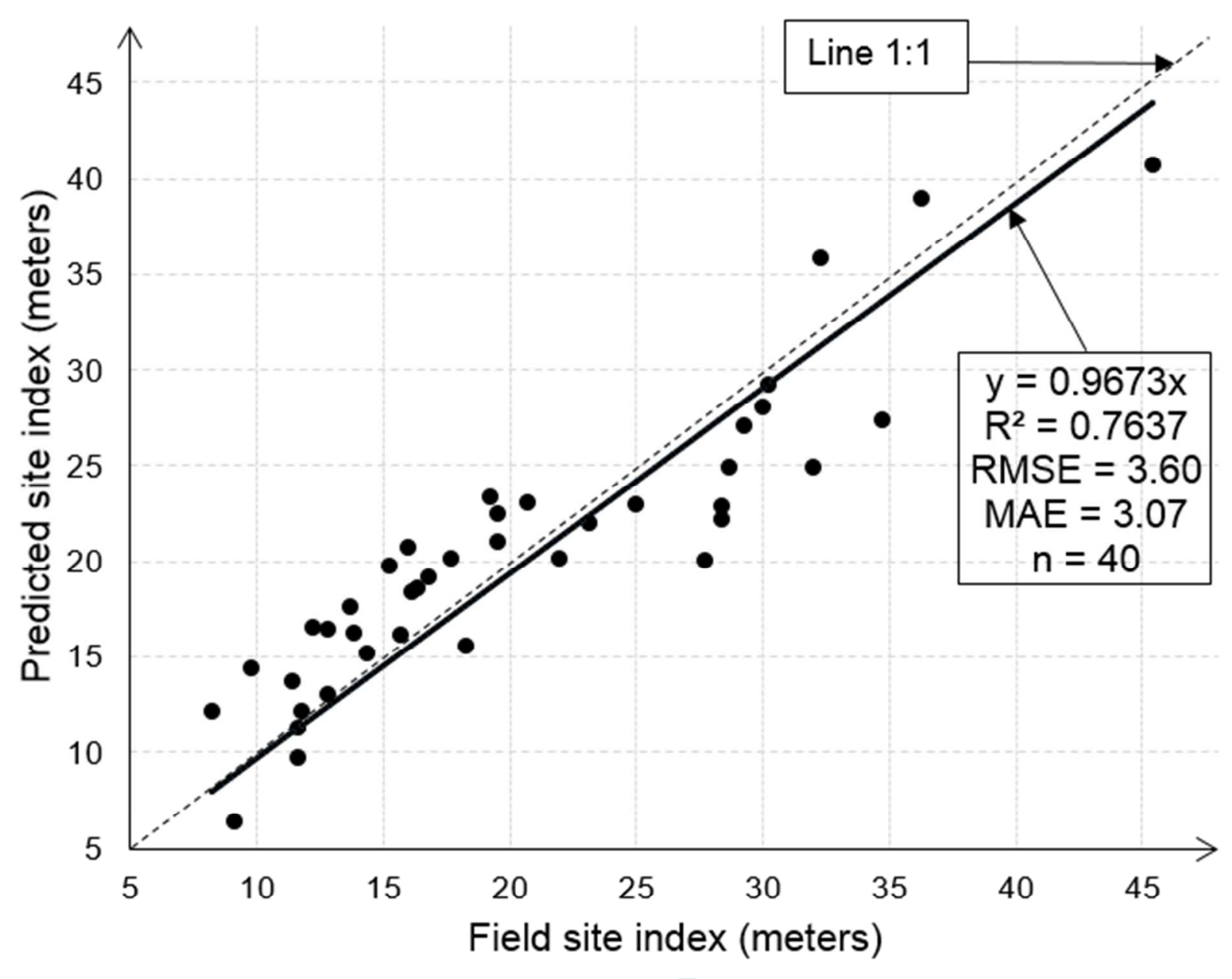

Figure 7. The comparison between field and predicted site index from 40 validation plots 


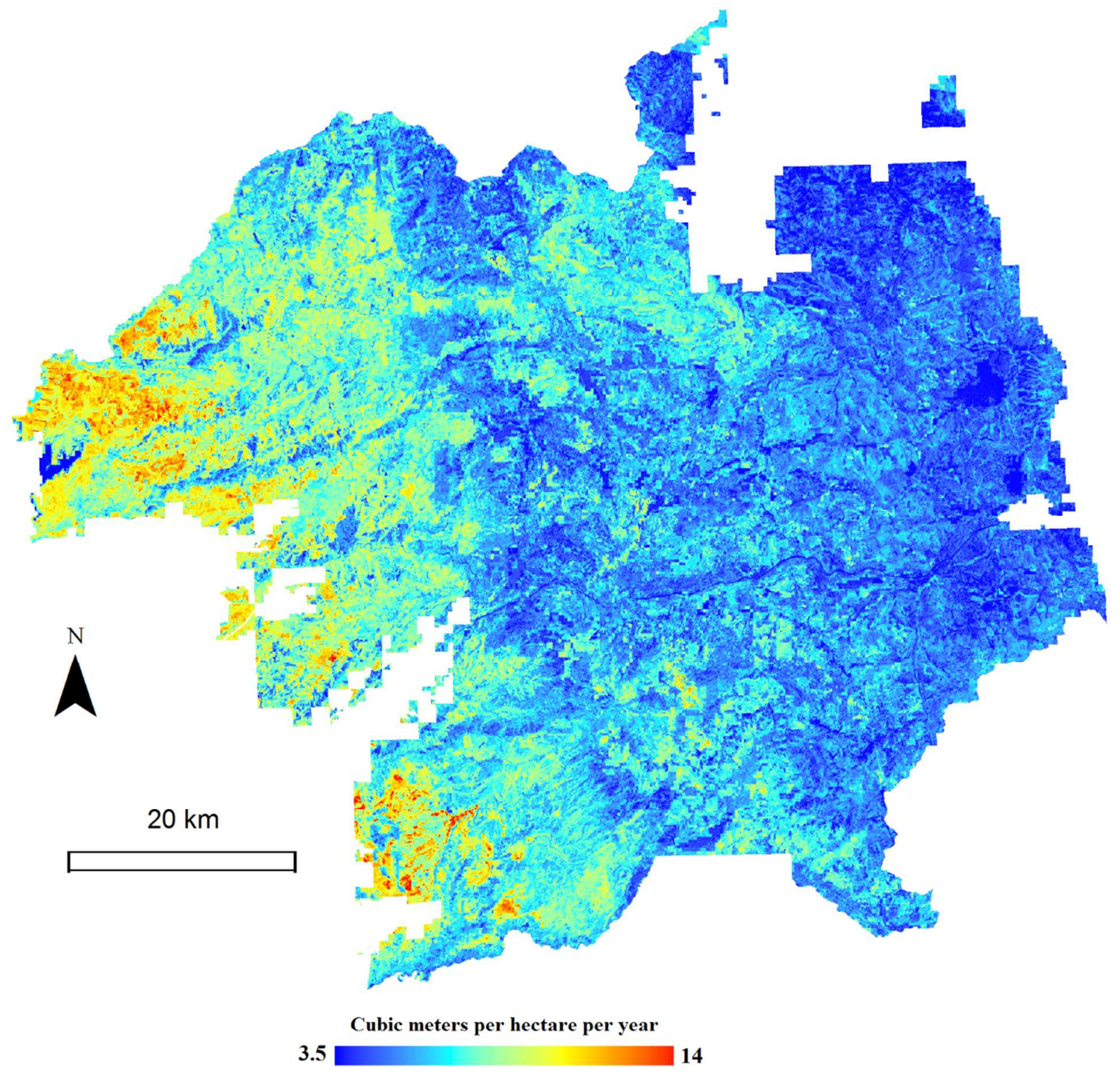

Figure 8. Mean annual increment (MAI) prediction in the Tahoe National Forest 


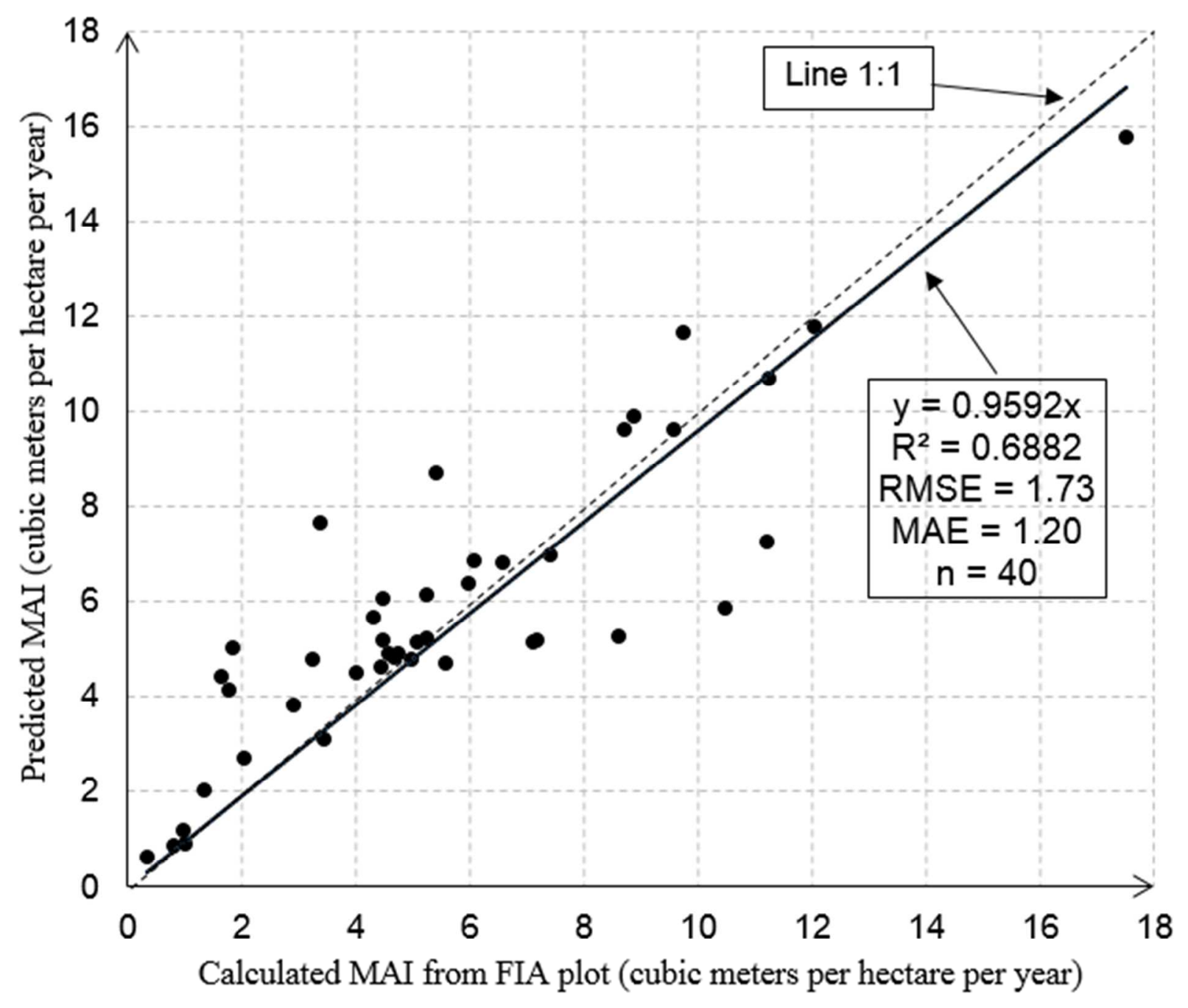

Figure 9. The comparison between field and predicted mean annual increment (MAI) from 40 validation plots 


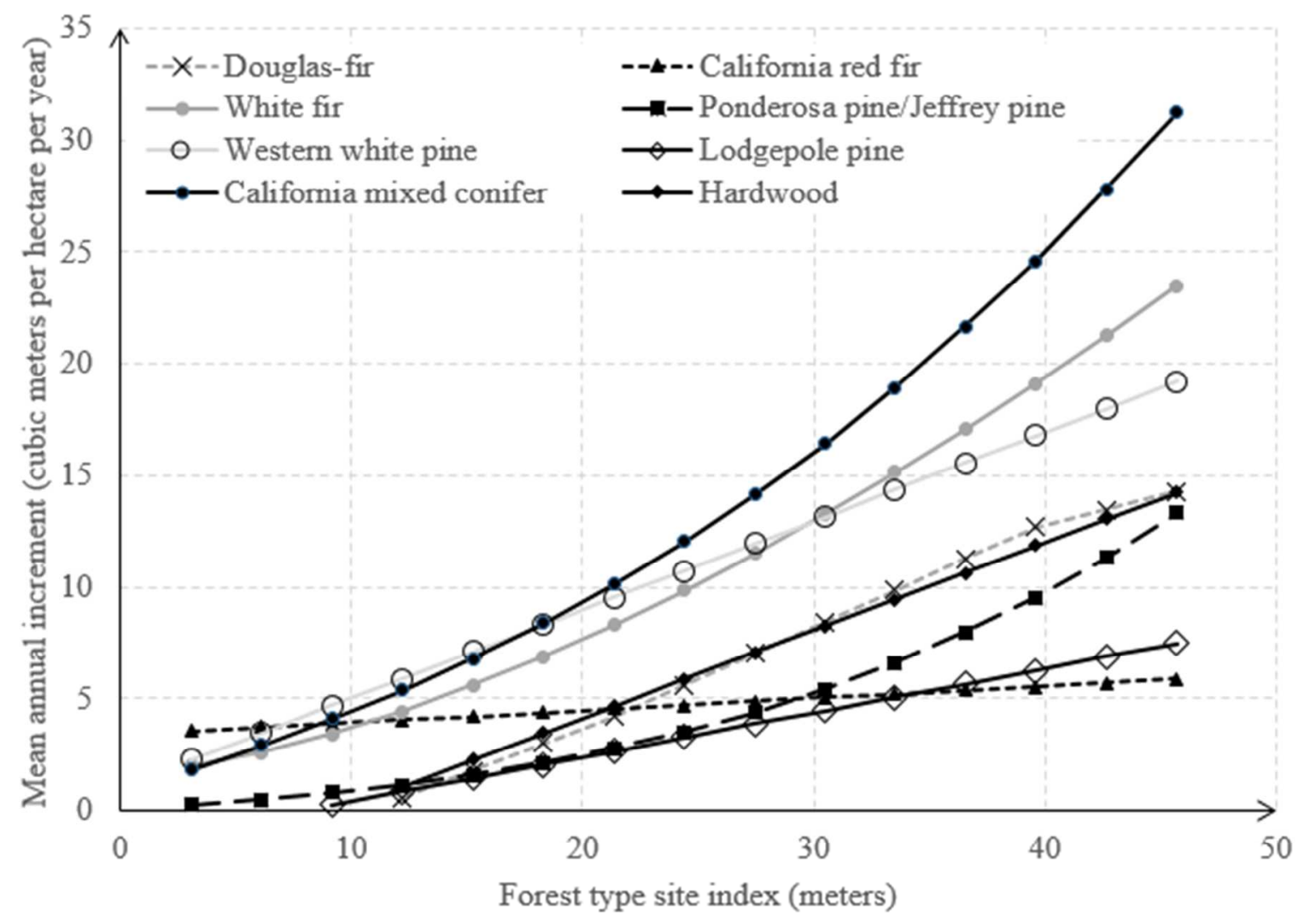

Figure 10. Mean annual increment (MAI) prediction curve from site index (SI) for different forest type 